\title{
Construction risk analysis of water environment treatment project based on WBS-RBS and AHP in flood period --Take the EPC project of comprehensive treatment of water environment in the east of a city as an example
}

\author{
Zhi Zheng ${ }^{1,2}$, Qi Wu Chen ${ }^{1}$, Tian Cheng Zhang ${ }^{1}$, Ren Jie Zhang ${ }^{1}$, Xing Fu Wang ${ }^{1}$ and Ce Ma ${ }^{1}$ \\ ${ }^{1}$ Changjiang Yichang Waterway Bureau, Yichang, 443003, China \\ ${ }^{2}$ School of Hydraulic Engineering, Changsha University of Science \& Technology, Changsha, 410114, China
}

\begin{abstract}
Basic environment construction is a livelihood project, especially water environment management is a hot topic in current engineering construction. There are more or fewer risks in the water environment treatment construction process, especially the black and smelly water treatment during the flood season. Hidden dangers, especially this year is the resumption of work and production after the epidemic, which coincides with the flood season. This article takes the EPC project of comprehensive water environment management in the east of a city as an example, and combines the WBS-RBS method and AHP analysis to analyze the risks of the water environment management project during the flood period. Analysis enables the project risk to be predicted in advance, and the risk is quantified, so that the risk coefficient is minimized and the project construction can proceed smoothly.
\end{abstract}

\section{Introduction}

As the economy continues to develop, Chinese government departments pay great attention to the environment. As leaders propose to protect and improve people's livelihood during development, it is necessary to establish and firmly believe that clear water and green mountains are the golden mountains and silver mountains. ${ }^{[1]}$ Black and smelly water treatment projects are under construction in our country. The treatment of black and smelly water bodies is generally divided into four aspects: internal source treatment, pollution interception engineering, ecological restoration engineering, and living water engineering. During the construction of black and odorous water bodies, there are many uncertain factors, so that there are many risks in the construction of black and odorous water bodies. In order to better achieve project goals, risk identification, assessment, response, and monitoring are indispensable parts of project management. There are many risk factors during the construction of black and odorous water bodies during the flood season.

At present, the methods of risk management mainly include Saman Aminbakhsh, Murat Gunduz, Rifat Sonmez, etc., based on the security cost theory, and proposed a security risk assessment framework (COS) model and analytic hierarchy process (AHP) ${ }^{[2]}$. Huu-Tho $\mathrm{N}$ et al. proposed an integrated multi-criteria decision model based on fuzzy analytic hierarchy process (AHP) and fuzzy additive ratio evaluation (ARAS) for the evaluation and selection of conveyors ${ }^{[3]}$.
Liu Yongqiang, Zhang Hongrui, Qian Bijun and others constructed a water conservancy project cost risk evaluation model based on triangular fuzzy numbers. It has been confirmed by practical application that the application of this model can improve the level of refined management of project cost of water conservancy construction enterprises, and has practical effects on cost management ${ }^{[4]}$.

At the end of 2019, the COVID-19 epidemic occurred, everyone was closed behind to fight the epidemic. During this period, our engineering projects were temporarily suspended accordingly. Construction was gradually recovered in May. After the restoration of the construction process, it coincided with the rainy season, therefore, the construction encountered a series of problems such as excessive water level and obstructed excavation. In order to avoid unnecessary losses during construction, taking the water environment treatment EPC project in the east part of a city as an example, the risk analysis and research related to construction during the flood period was launched under the epidemic prevention and control.

\section{Project Overview}

This project is located in an industrial park in the east of a city. The industrial park is adjacent to the tributary of the Yangtze River. The local area is the Dongting Lake alluvial plain, which belongs to quicksand geology and is rich in groundwater. The depth of the water level is 0.5-0.2 meters. -5000 tons/day; located in the

*Corresponding author's e-mail: wangyanyan@antelope.com 
subtropical transitional monsoon climate zone, the four seasons are distinct; the rainfall is uneven. The main construction content of this project includes four main channels and related tributaries in the park. Among them, the sewage interception project and the ecological restoration project are the first phase of the project, and the internal source treatment and the running water project are the second phase of the project.

\section{Risk identification of the project using WBS-RBS method}

method is a relatively complete work breakdown structure in modern project management. We decompose WBS according to the actual situation of the project, and establish the WBS-RBS method on the basis of WBS to identify the risks of this project.

This project mainly consists of four parts: endogenous treatment, pollution interception project, ecological restoration project, and running water project. We further decomposed on the basis of the four major parts, and we established a work breakdown structure for the EPC project in the east part of a city. As shown in Figure 1:

WBS (work Breakdown Structure) decomposition

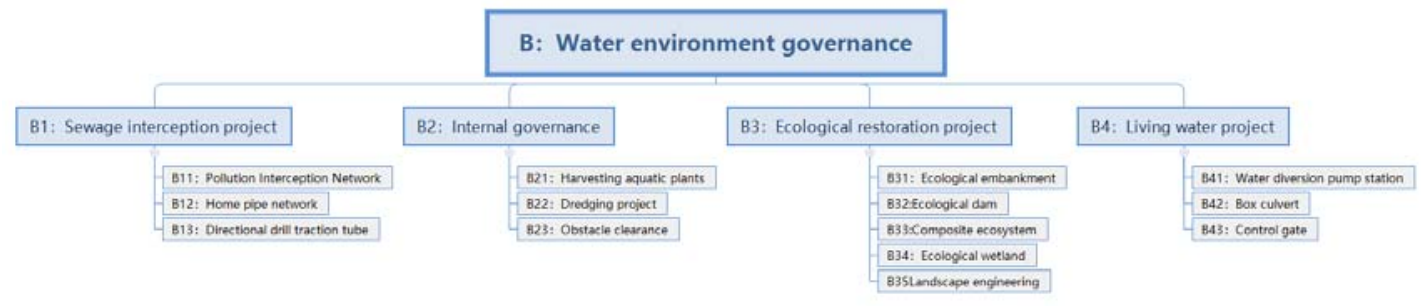

Figure 1.WBS decomposition structure of water environment comprehensive treatment EPC project in the east of a city during flood period construction

On the basis of the WBS structure in the above figure, perspective of the construction process during the flood we construct the RBS risk breakdown structure from the season, as shown in Figure 2:

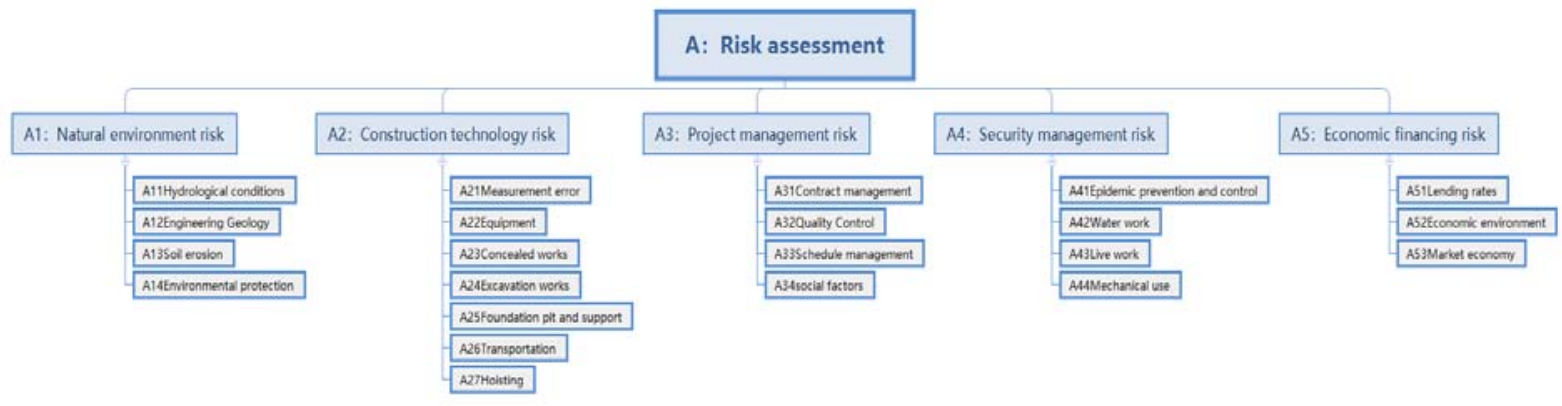

Figure 2. RBS breakdown structure during flood season construction of EPC project of comprehensive water environment management in the east of a city

According to the above structural decomposition diagram, the risks in the project can be judged. Combined with the actual situation of the project, the risk analysis is as follows:

\subsection{Natural environment risk}

The construction area belongs to the flood plain of Dongting Lake, where there are unfavorable geological conditions such as quicksand and underground rivers, and the water level is relatively high, which is not conducive to excavation and construction. In addition, during the flood season, the water level of the outer river is higher than that of the inland river, and the groundwater level rises. Improper response will cause geological disasters such as landslides and soil erosion during construction. In the process of comprehensive treatment of the water environment, the removal of silt in the water, the removal of water weeds, and the removal of weeds and trees on the shore are very important. In the removal process, it is necessary to clean up and prevent soil erosion and post-cleaning treatment. Silt stacking Improper cleaning and improper stacking will have environmental impact and form secondary pollution.

\subsection{Construction technology risk}

Any project will have uncertainty in the construction process. Therefore, when it comes to extreme hydrological conditions and engineering geological conditions during the unforeseen flood season, adjustments should be made according to the actual situation. The risk performance is mainly reflected in the following aspects: measurement error, equipment use, concealed engineering, foundation pit support, traffic Risk items such as transportation and lifting.

\subsection{Project management risk}

Water environment treatment projects are inherently special in the flood season, especially after the impact of 
the epidemic, the construction period is delayed, resulting in the phenomenon of over-hurrying the construction period, which leads to the risk of contract management. In the flood season, the water level is high, and the excavation is difficult so that the water level of the main runoff is high, which will cause quality and schedule problems in the accompany of certain social factors.

\subsection{Security management risk}

The safety issues of the comprehensive water environment management project during the flood season construction process are extremely important, especially when the current epidemic situation has not completely disappeared, epidemic prevention and control still need to be addressed. As most of the operations are on water and near water, electricity safety is a very important safety hazard. In the safety management during the construction process, live work, large machinery such as water excavators, cutter suction boats, etc. are in the flood season. Safety risks during construction must be strictly controlled.

\subsection{Financial financing risk}

This project is an EPC project. The total contract price is the basic point of lowering the total cost, and the

Table 1.WBS-RBS risk matrix for the construction of the EPC project in the flood period of the water environment comprehensive treatment in the east of a city payment method is slow. The time cost requirements for the initial financing funds are very strict. Especially after the suspension of work due to the epidemic, although the state has issued relevant reduction policies, The cost of financing funds is still one of the major sources of risk, especially during the flood season construction process, the construction progress is slow, the implementation of funds is small, and the risks of financial financing will still affect the overall operation.

\section{The project uses WBS-RBS method risk matrix}

Based on the relevant theoretical knowledge of WBS-RBS and the risk analysis of this project, the WBS-RBS matrix framework of the EPC project of comprehensive treatment of water environment in the east part of a city is constructed. Starting from the project goal, the project is gradually decomposed, and WBS is established at one time Dendrogram and risk RBS dendrogram, according to the interweaving of two tree diagrams to form WBS-RBS risk matrix for loss identification and analysis, one by one judge whether there is a risk in the risk point, and there is a risk. As shown in the following table:

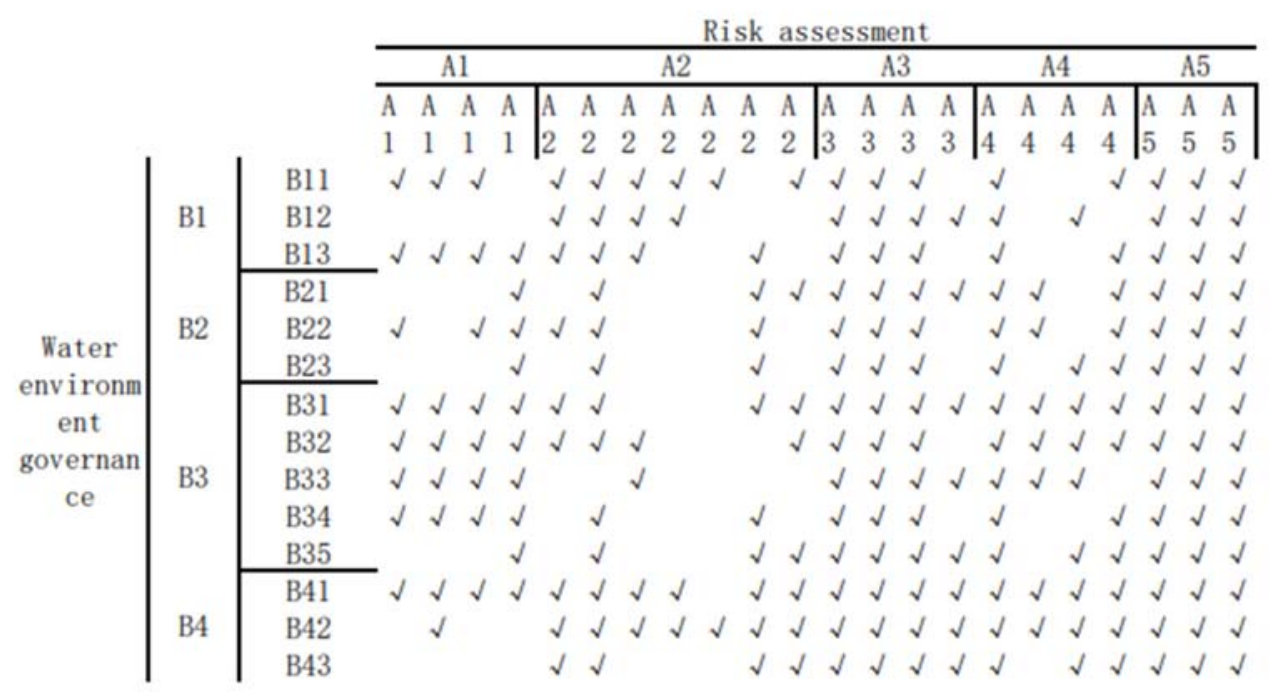

\section{Use AHP for weight calculation}

The risks unfolded through RBS are divided into two levels. The first level includes five major elements: natural environment risk, construction technology risk, engineering management risk, safety management style, and economic financing risk. The risk factors are expanded. Use fuzzy mathematics to calculate the weight, construct a judgment matrix by assigning risk factors, and check its consistency to obtain the weight vector [5], the specific method is as follows:
Using fuzzy numbers to express preferences, we sampled data from three experts to score. They compared a series of indicators. Each indicator has a fuzzy number, which is $\left(\mathrm{l}_{1}, \mathrm{~m}_{1}, \mathrm{u}_{1}\right)$, $\left(\mathrm{l}_{2}, \mathrm{~m}_{2}, \mathrm{u}_{2}\right),\left(\mathrm{l}_{3}, \mathrm{~m}_{3}, \mathrm{u}_{3}\right)$;

Integrate three fuzzy numbers into one $\left(\frac{l_{1}+l_{2}+l_{3}}{3}, \frac{m_{1}+m_{2}+m_{3}}{3}, \frac{u_{1}+u_{2}+u_{3}}{3}\right)$

Repeat the above steps until all the comparisons become a fuzzy number.

Calculate the comprehensive weight of each indicator: 
(1) The comprehensive fuzzy value $D_{i}^{k}$ (initial weight) of the K-level index $\mathrm{i}$ is calculated as follows:

$$
D_{i}^{k}=\sum_{j=1}^{n} a_{i j}^{k} \div\left(\sum_{i=1}^{n} \sum_{j=1}^{n} a_{i j}^{k}\right), i=1,2, \ldots, n
$$

(2) Defuzzification. And find the final weight.

$\mathrm{M} 1(11, \mathrm{~m} 1, \mathrm{u} 1)$ and $\mathrm{M} 2(12, \mathrm{~m} 2, \mathrm{u} 2)$ are triangular fuzzy numbers. The probability of $\mathrm{M} 1>\mathrm{M} 2$ is defined by the triangular ambiguity function as:

$$
\mathrm{P}\left(\mathrm{M}_{1} \geq \mathrm{M}_{2}\right)=\left\{\begin{array}{cc}
1 & \mathrm{~m}_{1} \geq \mathrm{m}_{2} \\
\frac{\mathrm{l}_{2}-\mathrm{u}_{1}}{\left(\mathrm{~m}_{1}-\mathrm{u}_{1}\right)-\left(\mathrm{m}_{2}-\mathrm{l}_{2}\right)} & \mathrm{m}_{1} \leq \mathrm{m}_{2}, \mathrm{u}_{1} \geq \mathrm{l}_{1} \\
0 & \text { other }
\end{array}\right.
$$

(3) Determine the weight of each indicator at other levels

Using the same method, the next level of indicator $\mathrm{Ai}$ weight Wi is obtained, then the total weight of indicator Ai:

$$
\mathrm{TW}_{\mathrm{i}}=\mathrm{W}_{\mathrm{C}_{\mathrm{m}}} \times \mathrm{W}_{\mathrm{i}}(\mathrm{m}=1,2,3,4 ; \mathrm{i}=1,2, \ldots 5)
$$

The total weight of the lower-level indicators is calculated.

The fuzzy evaluation matrix of criterion layer is obtained by calculation of this project:

$$
\begin{gathered}
\mathrm{W}_{\mathrm{C}_{\mathrm{m}}}=\left[\begin{array}{cccc}
0.58 & 0.55 & 0.40 & 0.50 \\
0.44 & 0.35 & 0.63 & 0.45 \\
0.29 & 0.33 & 0.33 & 0.33 \\
0.44 & 0.55 & 0.38 & 0.44 \\
0.44 & 0.39 & 0.44 & 0.50
\end{array}\right] \\
\mathrm{TW}_{\mathrm{i}}=\left[\begin{array}{lllll}
0.96 & 0.79 & 0.59 & 0.88 & 0.79
\end{array}\right]
\end{gathered}
$$

\section{Conclusion}

According to the data, the target-level risk of the EPC project of the comprehensive treatment of water environment is relatively low, and it is basically low-medium risk. According to the specific situation of the project, formulate risk response measures and control plans. After analyzing the above methods, it is found that project management risk $>$ construction technology risk $>$ natural environment risk $>$ safety management risk $>$ financial financing risk. When the project is constructed in the flood season, the project management risk is relatively high. Contract management and schedule control should be strengthened to keep pace with actual construction and construction period claims in special circumstances.

Due to the special circumstances during the epidemic and the flood season, the construction period was delayed. In order to avoid losses as much as possible and quickly resume production, a series of measures such as construction period claims can be adopted to minimize management risks. When the site conditions cannot meet the construction conditions, the construction can be appropriately suspended to avoid economic losses caused by construction technical risks. Due to the impact of the epidemic this year, higher authorities have also introduced many corresponding policies to minimize the risk of financial funds this year.

\section{Report}

According to the above research, both the EPC project of comprehensive water environment management under the current situation and even other projects under construction have experienced a long period of suspension. The construction has gradually resumed after the epidemic is basically controlled. There are all kinds of obvious or hidden risks. Before resuming production, it is necessary to predict the project risks and formulate response plans. It is an indispensable that the risks identified in advance ensure the smooth progress of the project.

\section{References}

1. Xi Jinping talks about the basic strategy for upholding and developing socialism with Chinese characteristics in the new era-Xinhua English.news.cn[EB/OL]. [2020-7-14]. http://www.xinhuanet.com//politics/2017-10/18/c _1121820368.htm.

2. Aminbakhsh S, Gunduz M, Sonmez R. Safety risk assessment using analytic hierarchy process (AHP) during planning and budgeting of construction projects[J]. Journal of Safety Research, 2013,46:99-105.

3. Huu-Tho N, Siti Z M D, Yusoff N, et al. An Integrated MCDM Model for Conveyor Equipment Evaluation and Selection in an FMC Based on a Fuzzy AHP and Fuzzy ARAS in the Presence of Vagueness[J]. PLOS ONE, 2016,11(4).

4. Liu Yongqiang, Zhang Hongrui, Qian Bijun. Research on cost risk management of water conservancy project based on FAHP[J]. Hydropower Energy Science, 2009,27(04):151-154.

5. Si Shoukui et al. Mathematical modeling algorithm and application[M]. National Defense Industry Press,2011. 